\title{
A Comparative Study on Weighting Factor Design Techniques for the Model Predictive Control of Power Electronics and Energy Conversion Systems
}

\author{
Oluleke Babayomi, Member, Yuzhe Zhang, Student Member, Yu Li, Student Member, Yongdu Wang, Student \\ Member, Zhen Li, Senior Member, and Zhenbin Zhang, Senior Member
}

\begin{abstract}
During the past decade, the model predictive control (MPC) of power electronics and drives has witnessed significant advancements in both dynamic performance and range of applications. However, researchers still encounter challenges with the optimal design of weighting factors, and this lowers the capabilities derivable from MPC. This study first reviews the different weighting factor design techniques proposed in the literature for power electronics and electrical drives (applied to wind/solar energy conversion, microgrids, grid-connected converters and other high performance converter-based systems). They are grouped under heuristic, offline tuning, sequential, and online optimization methods. Next, the study provides real-time hardware-in-the-loop comparative results for the implementation of four weighting factor design techniques on a grid-connected two-level back-to-back power converter-based permanent magnet synchronous generator wind turbine system. Through these laboratory results, the advantages and limitations of the different weighting factor design methods are highlighted.
\end{abstract}

Index Terms-Weighting factor, model predictive control, power electronics converters, drives, microgrid, wind turbine, permanent magnet synchronous generator (PMSG).

\section{INTRODUCTION}

Model predictive control is emerging as a popular control technique with application in cross-disciplinary domains. Over the past half-century, it has found industrial relevance to petrochemical, aerospace and automotive processing and manufacturing. Despite MPC's initial introduction to power electronics control in the 1980s, its ascendancy occurred in the past about two decades [1]. This resurgence has been attributed to the emergence of fast microprocessors with the capability for MPC's high computational need. MPC is grouped into finite control set MPC (FCS-MPC), and generalized predictive control [2]. However, FCS-MPC (also called direct MPC with reference tracking [1]) has been more studied because of its intuitive features and ease of application. Despite its advantages including high performance multi-objective control with constraints, FCS-MPC (simply called MPC going forward) is limited by several challenges - among these is the optimal weighting factor design.

The weighting factor is used to prioritize control objectives in the single cost function to be optimized in MPC-based multi-objective control. So, objectives with higher priority get higher weight assignments. Based on this principle, researchers usually adjust values assigned to weight factors heuristically until performance indices including total har- monic distortion (THD), tracking error, average switching frequency, and steady-state stability are attained. Nonetheless, this procedure hinders MPC's optimal performance. Therefore, researchers in this field have devised several alternative approaches to overcome this challenge. These can be categorized as offline heuristic weighting factor tuning, sequential MPC, simplified-model-based MPC, and online optimization tuning (comprising both artificial intelligence (AI) and non-AI-based methods) tuning approaches.

Sequential MPC methods, also called cascaded schemes in the literature, attempt to simplify the design process by indirectly achieving the purpose of the weighting factor, rendering it unnecessary [3]. Another method that avoids the weight factor is the simplified-model MPC. This can be applied where the competing control objectives can be analytically transformed into one parameter, so that all objectives have the same unit [4]-[6]. Online optimization tuning utilizes an optimization algorithm to select the optimal weighting factor, with respect to real-time plant and operational conditions [7], and could increase the computational burden of the controller. It comprises non-AI, and AI-based methods. AI-based online tuning schemes optimize the tuning process by using genetic algorithm, fuzzy logic and other AI schemes [8]. The AI methods have been shown to have relatively low computational requirements in control applications [9].

Review studies on MPC for power electronics and drives have been reported in past publications. Refs. [2], [10], [11] surveyed MPC of power converters with focus on both academic and industrial aspects of the prediction model, the cost function, and the optimization algorithm. The predictive torque control of switched reluctance machines drives was covered in [12], [13]. Techniques employed to reduce the computational burden of long predicition horizon-based MPC were reviewed in [14]. The authors of [15], [16] reviewed MPC applications for microgrid converters. However, none of these publications carried out a detailed study on the design of weighting factor for predictive control of converters and drives. Also, there is yet no study that provides a detailed quantitative comparison of the performance of different weighting factor design methods. To close this research gap, this study focuses specifically on the methods for designing weighting factors (or indirectly achieving their purpose, while avoiding their explicit use), which is a significant challenge that has been highlighted in several studies. We provide a detailed comparison of the design 
methods using their underlying mathematical principles, control schemes, and numerical results of dynamic performances.

The paper introduces the fundamentals of MPC and heuristic weighting factor tuning in Sec. II. Three weighting factor design methods are presented as follows: sequential MPC in Sec. III, simplified model MPC in Sec. IV, and online optimization-based tuning in Sec. V. Laboratory-based HiL case study and discussion are in Sec. VI. The emerging trends of this topic are covered in VII, and the conclusion is drawn in Sec. VIII.

\section{FUndAMENTALS OF MPC FOR POWER CONVERTERS}

In this section, the underlying principles of MPC are discussed, including the system model and weighting factor.

\section{A. System Model}

The generic discrete model of a power electronics system is given by (1), where $k \in \mathbb{N}$ is the discrete time step, $\mathbf{x}$ is the state vector (with state variables that include filter current/voltage, and machine fluxes [11]), $\mathbf{y}$ is the output vector (with output variables including output current, voltage, active/reactive power, speed and torque).

$$
\begin{aligned}
\mathbf{x}(k+1) & =\mathbf{f}(\mathbf{x}(k), \mathbf{u}(k)), \\
\mathbf{y} & =\mathbf{x}(k) .
\end{aligned}
$$

Given a sequence of input variables over a prediction horizon $N_{p} \in \mathbb{N}$ time steps. We can define a sequence of possible power converter switching states that the controller could implement as [11], [17]:

$$
\mathbf{U}(k)=\left[\begin{array}{llll}
\mathbf{u}^{T}(k) & \mathbf{u}^{T}(k+1) & \ldots & \mathbf{u}^{T}\left(k+N_{p}-1\right)
\end{array}\right] .
$$

The predictive controller seeks an optimal switching sequence

$$
\mathbf{U}_{\text {opt }}(k)=\min _{\mathbf{U}(k)} J,
$$

where $J$ is the cost function that captures the control objectives for the optimization problem. In power electronics systems, the control objective could track a reference by minimizing a tracking error magnitude as

$$
J=\sum_{k=1}^{k+N_{p}-1}\left\|\mathbf{y}^{p}(k+1)-\mathbf{y}^{*}(k+1)\right\|_{\mathbf{Q}}^{2}+\lambda_{\mathrm{u}}\|\Delta u(k)\|_{2}^{2},
$$

where $\mathbf{Q}$ is the penalty matrix on the tracking error, $\mathbf{y}^{p}$ is the predicted output, $\mathbf{y}^{*}$ is the reference, $\lambda_{\mathrm{u}}$ penalizes the control effort $\Delta u(k)$, and $\Delta u(k):=u(k)-u(k-1)$. MPC is a receding horizon scheme; therefore, only the first term of the sequence $\mathbf{U}_{\text {opt }}(k)$ is applied to the plant. Recalculation of the next sampling instant's predictions and optimal sequence is done after updated measurements/estimates of the states.

Detailed discussions on holistic design considerations for MPC, including prediction horizon, control effort, weighting factor and performance assessment are outside the scope of this article, but can be found in [1]. In this work, focus will be on the design methods for optimal weighting factor tuning.

\section{B. Heuristic Weighting Factor Tuning}

As earlier mentioned, MPC has the capability to facilitate the optimal control of the multi-objective terms/parameters in a predictive cost function. Some of these parameters could have equal control priorities; for instance, active and reactive power in grid-connected converters [18]-[20]. However, other control objectives have differing priorities; e.g., the control of torque and flux in electrical machine drives. The latter case needs weighting factors to set a relative importance between control objectives for optimal system performance (e.g. low current THD). Although the conventional means of determining the value of the weighting factors is through offline heuristic tuning (according to rules provided in [21]), this results in sub-optimal control results [1]. In the following discourse, proposed alternative solutions in the literature will be subjected to objective analyses, highlighting the advantages and disadvantages associated with each method.

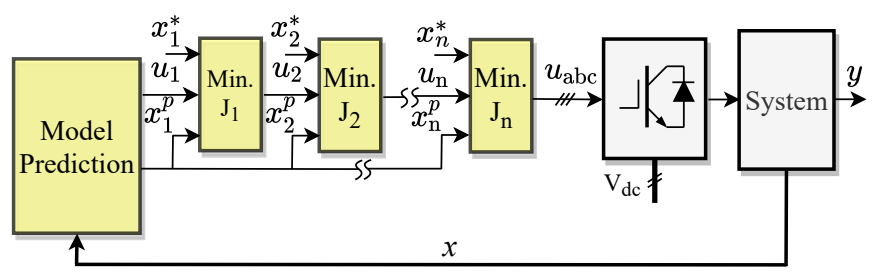

Fig. 1. Generic sequential MPC [3].

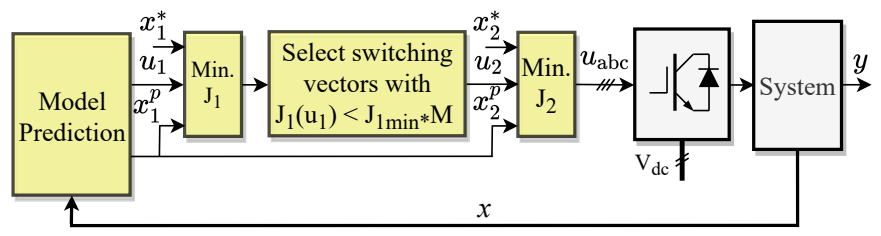

Fig. 2. Dynamic sequential MPC [22].

\section{Sequential Model Predictive Control}

Sequential MPC is a relatively new method that proffers a solution to the challenges associated with tuning weighting factors for MPC of power electronic converters. This method was introduced by [3], and operates on the concept of using multiple cost functions arranged in a cascaded/sequential order of computational execution as shown in Fig. 1. In the figure, $n$ cost functions are arranged sequentially, in decreasing order of priority, representing the initial cost function $J$ (5) broken into cascaded cost functions $J_{1}$ to $J_{\mathrm{n}}(6)$. Note that $x_{\mathrm{i}}^{\text {pred }}$ is the predicted term, and $x_{\mathrm{i}}^{*}$ is the reference $\forall i \in\{1,2, \ldots, n\}$. After the model prediction stage, the first cost function (representing the criterion of highest priority) is executed. The output of block $J_{1}$ comprises a sorted list of selected optimal voltage vectors that will be made available to all subsequent cost function stages $J_{2}$ to $J_{n}$. Stages $J_{2}$ to $J_{n}$ each optimize their individual cost functions with information about the prediction model and references. The final stage $J_{n}$ will provide the switching signals $S_{\mathrm{abc}}$ of the overall optimal voltage vector for each sampling time. The sequential MPC methods are different 


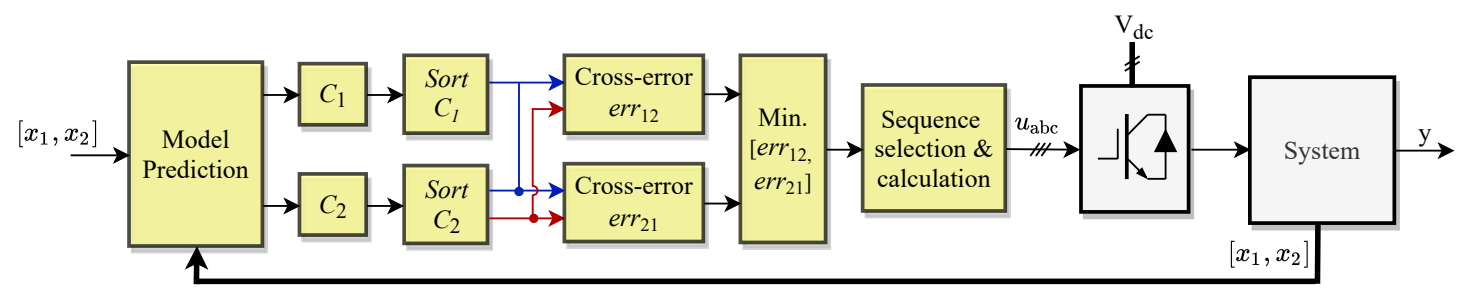

Fig. 3. Even-handed sequential MPC [23].

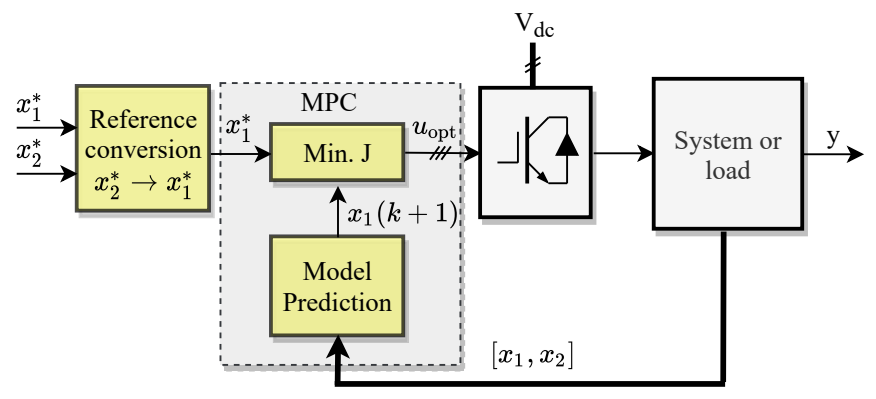

Fig. 4. Generic simplified FCS-MPC of power electronics systems.

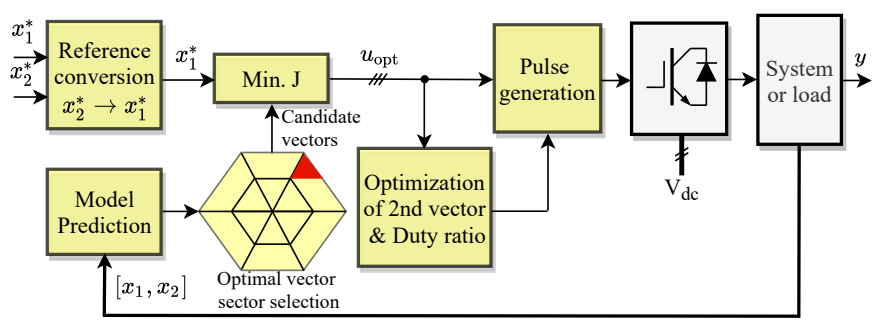

Fig. 5. Simplified FCS-MPC with 2-vector control for electrical drives [4], [24].

from the multi-cost-function method presented in [25] which utilizes the average of different cost-function ranks.

$$
\begin{aligned}
J=\left|x_{1}^{\text {pred }}-x_{1}^{*}\right|+\lambda_{\mathrm{x} 2}\left|x_{2}^{\text {pred }}-x_{2}^{*}\right|+\ldots+\lambda_{\mathrm{xn}}\left|x_{n}^{\text {pred }}-x_{n}^{*}\right| & \\
J_{1} & =\left|x_{1}^{\text {pred }}-x_{1}^{*}\right| \\
J_{2} & =\left|x_{2}^{\text {pred }}-x_{2}^{*}\right|, \ldots \\
J_{\mathrm{n}} & =\left|x_{\mathrm{n}}^{\text {pred }}-x_{\mathrm{n}}^{*}\right|
\end{aligned}
$$

Two challenges arise with the basic sequential MPC: i) the number of selected switching vectors from each stage could be too limited for optimal control of subsequent stages, and ii) because the first stage is implicitly given highest priority, there is a problem with applications where all criteria/cost functions have equal priorities. The first challenge is addressed (to an extent) by the dynamic sequential MPC [22], and the second challenge is solved by the generalized sequential MPC [26] and even-handed MPC [23]. The dynamic sequential MPC (shown in Fig. 2) adaptively modifies the sorted list of selected optimal voltage vectors from each stage to include all vectors that satisfy a minimum error criterion [22]; thus giving a better dynamic performance than when a static number of switching vectors is selected. Furthermore, both the generalized sequential MPC [26] and even-handed MPC [23] overcome the challenge inherent in a fixed sequence of execution of the cost functions. The even-handed method shown in (Fig. 3), for instance, adaptively selects the order of execution, based on the simultaneous optimality of all criteria by a cross-error minimization process. It is especially beneficial to multiple cost-functions with identical priorities.

The even-handed sequential method operates by minimizing cross-errors among control objectives, instead of minimizing the tracking errors of individual objectives. For instance, if we have a two-level inverter with seven unique voltage vectors $u_{i} \mid i=\{0,2, . ., 6\}$ (only one of two zero voltage vectors is considered), and the control objectives are for signals $x_{1}$ and $x_{2}$ to track their references $x_{1}^{*}$ and $x_{2}^{*}$, the criteria $C_{1}, C_{2}$ can be generated by normalization of the predicted errors for predicted terms $x_{1}^{p}$ and $x_{2}^{p}$ (where $x_{1 \text { rated }}$ and $x_{2 \text { rated }}$ are the rated values of signals $x_{1}$ and $x_{2}$ ):

$$
\begin{gathered}
C_{1}=\frac{\left|x_{1}^{p}-x_{1}^{*}\right|}{x_{1 \text { rated }}}, \forall i=\{0,2, . ., 6\} \\
C_{2}=\frac{\left|x_{2}^{p}-x_{2}^{*}\right|}{x_{2 \text { rated }}}, \forall i=\{0,2, . ., 6\}
\end{gathered}
$$

Using only the above criteria for minimization will give overall sub-optimal results because when a voltage vector is highly optimal for criterion $C_{1}$, it may not be optimal for $C_{1}$, and yet both criteria are supposed to be treated with equal priority. Therefore, to choose this optimal candidate requires that the cross-errors are ranked and minimized. At each sampling instant, the criteria are sorted and ranked for the eight voltage vectors from 1 to $8:\left(C_{1 \mathrm{r} 1}, C_{1 \mathrm{r} 2}, \ldots, C_{1 \mathrm{r} 8}\right)$, and $\left(C_{2 \mathrm{r} 1}, C_{2 \mathrm{r} 2}, \ldots, C_{2 \mathrm{r} 8}\right)$. The top three ranks are selected for the cross-error stage:

$$
\begin{aligned}
\operatorname{err}_{12} & =\left\{\left(C_{2 \mathrm{r} 1}-C_{1 \min }\right),\left(C_{2 \mathrm{r} 2}-C_{1 \min }\right),\left(C_{2 \mathrm{r} 3}-C_{1 \min }\right)\right\} \\
& =C_{2(r 1 ., r 2, r 3)}-C_{1 \min } \\
e r r_{21} & =\left\{\left(C_{1 \mathrm{r} 1}-C_{2 \min }\right),\left(C_{2 \mathrm{r} 2}-C_{2 \min }\right),\left(C_{2 \mathrm{r} 3}-C_{2 \min }\right)\right\} \\
& =C_{2(\mathrm{r} 1, \mathrm{r} 2, \mathrm{r} 3)}-C_{2 \min }
\end{aligned}
$$

Despite their relative ease of implementation, sequential MPC techniques have been shown to result in sub-optimal performance [1] to optimally-tuned weighting factors. 


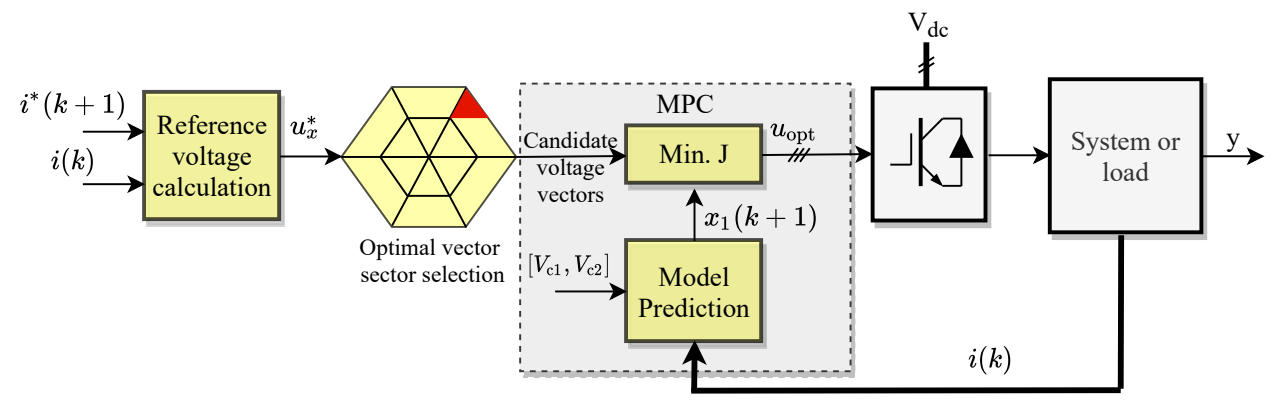

Fig. 6. Generic simplified FCS-MPC for multilevel converters [27].

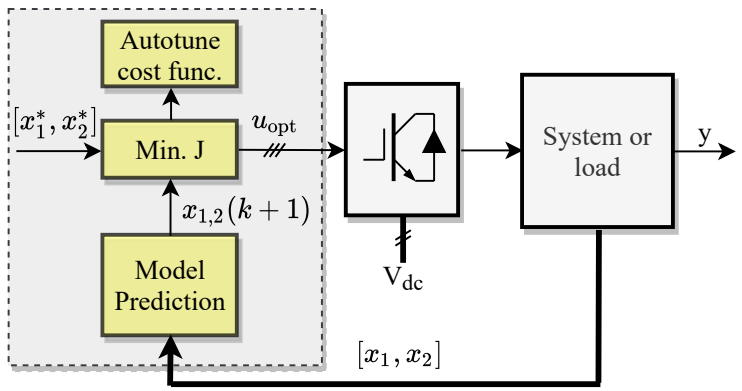

Fig. 7. Online autotuning of weighting factor-tuned weighting factor applied to the next sampling instant [7], [28], [29].

\section{Simplified-Model-BASEd MPC}

Simplified-model-based MPC methods aim to avoid the use of weighting factors by unifying the control objectives. This is possible where these control objectives are (in)directly interrelated. For instance, flux and torque can be unified in drive applications [4]-[6], [24], [30]-[35]. Also, the model of multilevel converters can be simplified by reducing the number of switching states or introducing redundant voltage vectors, without sacrificing good control performance [36]-[40]. The two cases of this method, i.e., unified control objectives and reduced switching states will be discussed in detail in this section.

The overall control scheme of simplified model MPC with unified control objectives is shown in Fig. 4 for a generic power electronics system. It involves three basic control stages: state prediction, reference conversion, and cost function minimization. Without loss of generality, the figure applies to the case where two states $\left(x_{1}\right.$ and $\left.x_{2}\right)$ are desired to be controlled via a single predictive cost function, without the use of a weighting factor. Since these states are usually in different units, e.g., flux and torque, the most defining step of this method is the reference conversion of both states to the same unit. This could be done by conversion of one state's reference to the other (e.g. $x_{2}^{*}$ to $x_{1}^{*}$, or vice-versa) as was done in [4]-[6], [24], [24], [30]-[35] via torque to flux reference, and flux to torque reference [41], [42] conversion. Alternatively, a third variable $\zeta$ could be introduced, and both references, $x_{1}^{*}$ and $x_{2}^{*}$, can be converted to $\zeta^{*}$, as was done in [4] (flux and torque to voltage reference). For improved steady-state performance, modifications to Fig. 4 can include the use of two optimal switching voltage vectors per cycle, instead of one. To achieve this, two stages can be added for second voltage vector selection, duty ratio optimization, and pulse generation control (Fig. 5) [4], [24].

The use of reduced switching states/redundant voltage vectors is the means of simplifying the MPC of multilevel converters like neutral-point clamped converter [40], [43], nested neutral-point clamped converter [44], matrix converter [45], rectifiers [43], [46] and quasi-Z-source converter [47].= These converters are modeled with per-phase (e.g. MMC for HVDC [27], [36]-[39], [48]-[51]), and the three-phase concepts (e.g. motor drives [45]). Details on these mathematical models are outside the scope of this paper, but can be found in [52]. The control objectives include the control of DC-link current ripple, sub-module voltage ripple, circulating current, output current, and sub-module capacitor voltage. Furthermore, while most studies were on FCS-MPC, few like [46], [49]-[51] reported work on modulated MPC with constant switching frequency.

Due to the modular design of multilevel converters, as the number of sub-modules/cells increases, so does the calculation burden of the control scheme. Therefore, to decrease computational burden, the literature reduces the applied switching states. Fig. 6 shows the simplified MPC scheme applied to multilevel converters. It requires a current reference generation stage which is used to optimize the cost function $J$. This is not done for all the available switching states, which could be as large as $(N+1)^{3}$, where $\mathrm{N}$ is the number of sub-modules per arm. Instead, an optimized set of redundant voltage vectors is generated for the cost function optimization process, reducing the computational burden to $3(N+4)$ [27]. The literature has focused significantly on applying variants of this scheme to modular multilevel converters for HVDC [27], [36]-[39], [43], [48]-[51]. Among these, only [46], [49]-[51] are designed for modulated MPC with fixed switching frequencies, while all others have variable switching frequencies.

\section{Online Optimization Methods}

In this section, online calculation of optimal weight factor will be discussed under headings of AI-based tuning, and nonAI-based optimization.

\section{A. Artificial Intelligence-Based Tuning Methods}

Artificial intelligence (AI) is associated with enabling machines with intelligence that mimicks human learning and 


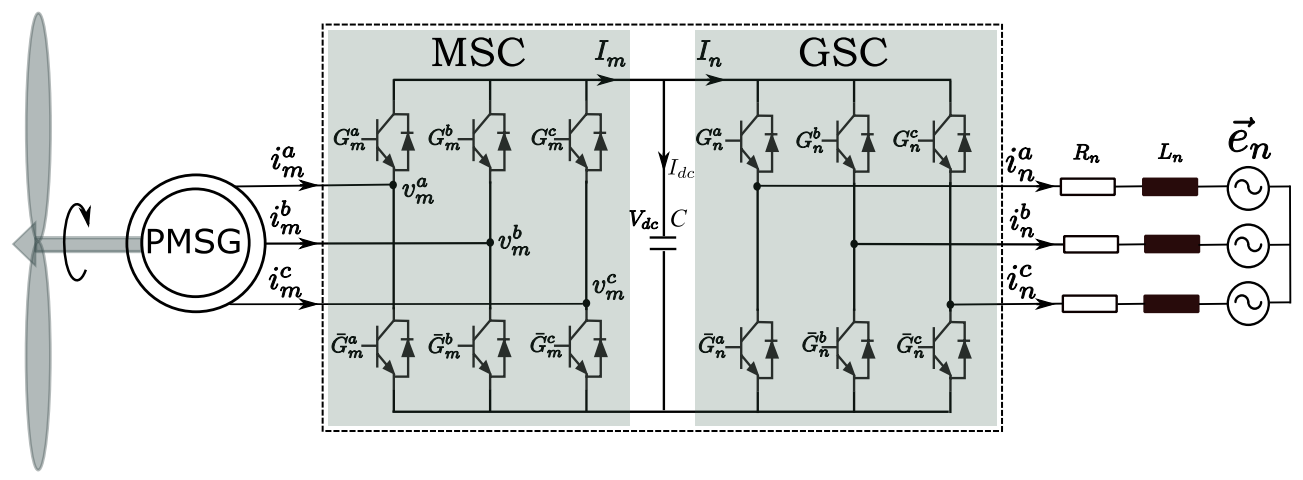

Fig. 8. Simplified power circuit of a grid-connected 'voltage source back-to-back power converter PMSG wind turbine system with RL filter, where $i_{m}^{a b c}$ and $i_{n}^{a b c}$ are the generator and grid-side current vectors, respectively; $v_{m}^{a b c}$ is the output voltage vector of the generator; $\mathbf{e}_{\mathbf{n}}$ is the grid voltage vector; $R_{n}$ and $L_{n}$ are the filter stator resistance and inductance, respectively.

reasoning [53]. In the broad field of power electronics, four groups of AI techniques have been applied, namely: expert system, fuzzy logic, metaheuristic techniques and machine learning [53]. Among these, the latter three have been applied to MPC weighting factor design in the literature.

Fuzzy logic - the most popular among AI methods in weighting factor design-forms rules with Boolean logic, taking uncertainties into consideration. It has been applied to direct matrix converter [54], three-level neutral point-clamped converter [55] and electrical machine drives [56]-[61]

Metaheuristic techniques (e.g. genetic algorithm, particle swarm optimization) utilize biological process for mathematical optimization [53]. A multi-objective genetic algorithm was employed in [8], [62] to tune weighting factors for torque, flux and switching frequency in the model predictive torque control of an induction motor drive. The dynamic performance was reportedly better that using a heuristic tuning process. Machine learning is categorized as supervised learning (uses labelled training dataset), unsupervised learning (uses unlabelled dataset) and reinforcement learning (does not require training dataset) [53]. Among several existing machine learning methods, only neural network (a form of supervised learning) has been applied to online weighting factor optimization. It has been used for three level neutral-point clamped converter [63], two-level voltage source converter [64], predictive torque control of an induction machine [9]. In contrast to the previous methods that are trained offline, an online self-training neuralnetwork method was proposed in [65] for seven-level modified packed U-cell (MPUC7) active rectifier. It combines particle swarm algorithm optimization for multi-weight factor tuning and a decoupled Lyapunov stability objective to guarantee control stability. In summary, machine learning methods are notable and have promising potential because they do not add significantly to computational burden, meanwhile, they work with high accuracy.

\section{B. Non-AI-based Online Optimization}

Online optimization techniques carry out real-time optimization of the weighting factors in multi-objective predictive control of power converters. Since all calculations required to accurately determine the optimal weighting factor are done online, these techniques generally increase the computational burden of the predictive control process. Methods employed in the literature include: tracking error optimization [7], [28], [29], [66]-[68], torque ripple optimization [69], [70], coefficient of variation [71], state normalization/variable sensitivity balance [72], look-up table [73], [74], grey relational analysis [75] and continuous function of pre-existing error [76]. To facilitate the optimal weight factor calculation for predictive torque and flux control in particular, algebraic methods are presented in [69], [77], and these are not computationallyintensive. Fig. 7, depicts an example for online autotuning of weighting factors which are applied to the next sampling time.

\section{HARDWARE-IN-THE-LOOP CASE STUDY}

In the section, a comparative study of four control methods based on HiL realization of a two-level back-to-back power converter-based permanent magnet synchronous generator wind turbine system. The system description and discussion of results are covered in the following.

\section{A. System Description and Modeling}

Fig. 8 illustrates the system to be controlled. It comprises a machine-side converter (MSC) that functions as an active front-end rectifier, connected to a DC-link capacitor, which supplies a grid-connected converter (GSC). For modeling simplicity, the wind turbine is directly mounted on the PMSG shaft without any interfacing gear box. System parameters are provided in Table I.

In order to stay within the scope of this paper the details of the mathematical models and state predictions for the MSC and GSC can be found in [78], [79], and will not be repeated here. We desire to compare the control characteristics for classical heuristically-tuned MPC, sequential MPC, evenhanded sequential MPC and online-tuned weighting factorbased MPC.

The MSC control objectives are: $\left(O b j_{\mathrm{m} 1}\right)$ accurate torque tracking with fast dynamics, and $\left(O b j_{\mathrm{m} 2}\right)$ maximum-torqueper-ampere current tracking. $\left(O b j_{\mathrm{m} 1}\right)$ and $\left(O b j_{\mathrm{m} 2}\right)$ are both captured in the current tracking cost function which does not require a weighting factor [79]:

$$
J_{m}=\left(i_{m}^{q *}-i_{m}^{q}(k+1)\right)^{2}+\left(0-i_{m}^{d}(k+1)\right)^{2},
$$


where $i_{m}^{q *}, i_{m}^{q}(k+1)$, are the reference and predicted q-axis current terms, and the d-axis current $i_{m}^{q}(k+1)$ tracks a zero reference for unity power factor control.

For the GSC control, the control objectives are: $\left(O b j_{\mathrm{g} 1}\right)$ reference tracking of active power and $\left(O b j_{\mathrm{g} 2}\right)$ reference tracking of reactive power, captured in the cost function $J_{g}$ :

$$
J_{g}=\left(P^{*}-P(k+1)\right)^{2}+\lambda_{\mathrm{Q}}\left(Q^{*}-Q(k+1)\right)^{2},
$$

where $\left\{y^{*}, y(k+1)\right\} \mid y \in\{P, Q\}$ represent the reference and predicted terms respectively. During normal conditions, $\lambda_{\mathrm{Q}}=$ 1 for equal priorities of active and reactive power tracking of their respective references; but when there is a mismatch in the grid-side filter $L_{\mathrm{n}}$ (Fig. 8), the weight factor becomes beneficial to improve robustness [28].

Four control schemes were implemented on real-time HiL PLECS RT-Box-1 devices (Fig. 9) and compared; the control schemes in the corresponding literature were implemented on the system: classical MPC [78], sequential MPC [79], [80], even-handed sequential MPC [23], and online-tuned weighting factor-based MPC [28].

TABLE I

HIL PARAMETERS FOR THE TEST SYSTEM.

\begin{tabular}{lll}
\hline \hline Parameters & Symbols & Values \\
\hline Generator stator resistance & $R_{\mathrm{s}}$ & $0.1379 \Omega$ \\
Generator stator inductance & $L_{\mathrm{s}}$ & $19.43 \mathrm{mH}$ \\
Nominal voltage & $V_{\text {nom }}$ & $250 \mathrm{~V}$ \\
Generator pole pairs & $N_{\mathrm{p}}$ & 3 \\
Sampling time & $T_{\mathrm{s}}$ & $20 \mu \mathrm{s}$ \\
Rotor permanent magnet flux & $\phi_{\mathrm{pm}}$ & $0.4268 \mathrm{~Wb}$ \\
DC-link capacitance & $C$ & $1100 \mu \mathrm{F}$ \\
Grid-side filter resistance & $R_{\mathrm{n}}$ & $0.015 \Omega$ \\
Grid-side filter inductance & $L_{\mathrm{n}}$ & $16 \mathrm{mH}$ \\
Grid-side phase voltage (peak) & $\left|e_{n}^{a b c}\right|$ & $210 \mathrm{~V}$ \\
Grid-side voltage frequency & $\omega_{\mathrm{n}}$ & $100 \pi$ \\
\hline
\end{tabular}

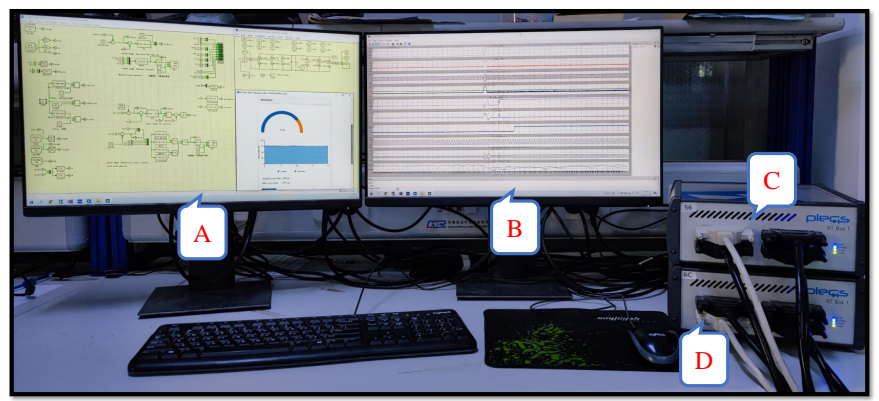

Fig. 9. Real-time HiL test-bench: A-PLECS user interface, B-signal monitor, C-real-time controller, and D-plant emulator.

\section{B. Discussion of Results}

Fig. 10 shows the overall control performances without any mismatch in the model parameters. For all the four plots, three step-parameter-changes were effected to test the transient performance of the control schemes. The speed reference was changed from 0.85 p.u. to 1.15 p.u. at 0.06 sec. A 1.8 p.u. pulse $q$-axis stator current reference change was initiated between
$0.06-0.075 \mathrm{sec}$. The DC-link voltage $V_{d c}$ was changed by +0.1 p.u. at $0.12 \mathrm{sec}$. The $d$-axis stator current reference was maintained at zero throughout the test interval.

The performances of DC-link voltage and active power tracking for the four schemes were identical in rapid response and low level of ripples. On the other hand, the even-handed MPC scheme had the best tracking performance with no spikes during all the transients earlier described. The online-tuned weighting factor method had good tracking with second lowest reactive power spikes during transients. Sequential MPC had low ripples, but the highest reactive power tracking error. All the four methods also had identical variable switching frequencies that ranged between $3.5-5.0 \mathrm{kHz}$.

Fig. 11 shows the overall control performances when the actual grid-side filter inductance was set to $1.5 L_{\mathrm{n}}$ versus $L_{\mathrm{n}}$ in the controller. The same transients earlier described for the case without parameter mismatch were applied. Just like in the previous case, the performances of DC-link voltage and active power tracking for the four schemes were identical in rapid response and low level of ripples. Although evenhanded sequential MPC had the highest voltage overshoot after the reference voltage step change, it produced the best overall performance for reactive power tracking. However, the tracking accuracy of classical MPC was the worst in the case of parametric mismatch. These results point to the fact that for the system tested in this study, even-handed sequential MPC had the most robust features: it produced the best reactive power tracking performance during transients and also under model parameter uncertainties. It also produced the least ripples of all the four methods under all testing conditions.

\section{FUTURE TRENDS}

The trend of development in the design of optimal weighting factor for the predictive control of power electronics and motor drives indicate potentials for significant advancements through emerging methods. First is the use of AI methods that maximize the availability of data made available through simulations and experiments. AI techniques, e.g. machine learning and ANN, when properly deployed, have high performance at low computational expense (as earlier discussed in Sec. V-A). Although they could be initially challenging due to the need for large amounts of data, and the large computational time that could result to train the developed AI model. However, this hurdle is being surmounted by the use of multiple processors and cores for CPU-training [64].

Also, although online optimization schemes offer a huge promise in respect of optimal weighting factor tuning, they are limited by high computational cost. Therefore, low computational algebraic optimization methods will be beneficial. Finally, hybrid weight-factor design methods that combine features of two or more of the four methods described above are expected to become more popular. For example, [81], [82] applied sequential MPC with computationally efficient selection of switching states to a three-level neutral-pointclamped inverter-based induction motor drive. 


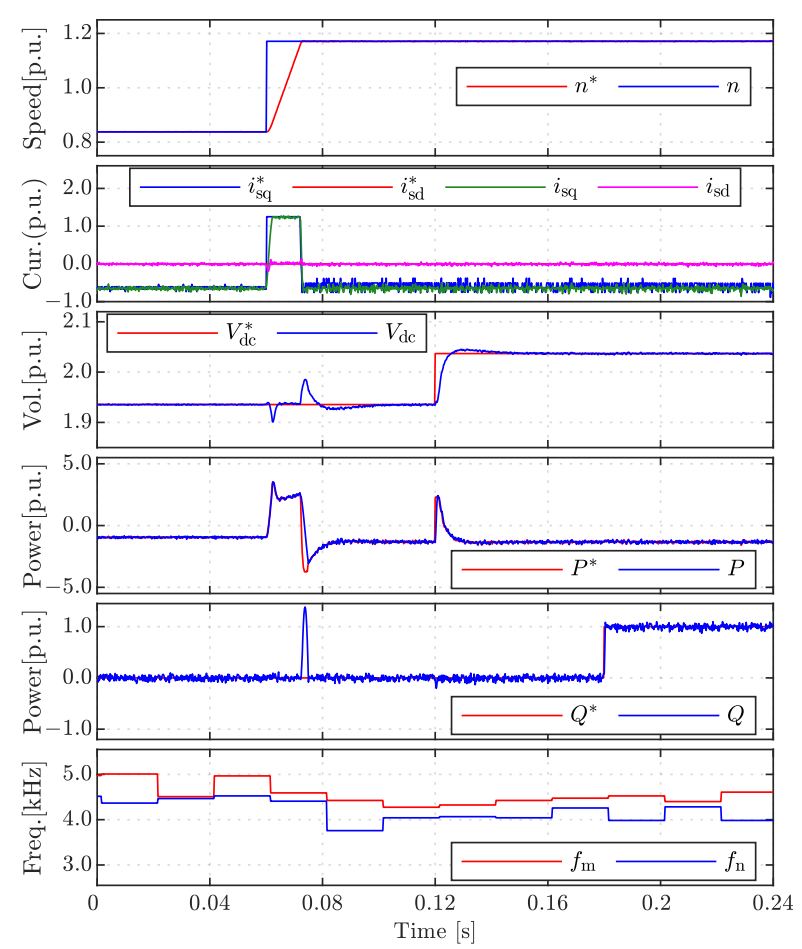

(a) Classical MPC (CMPC)

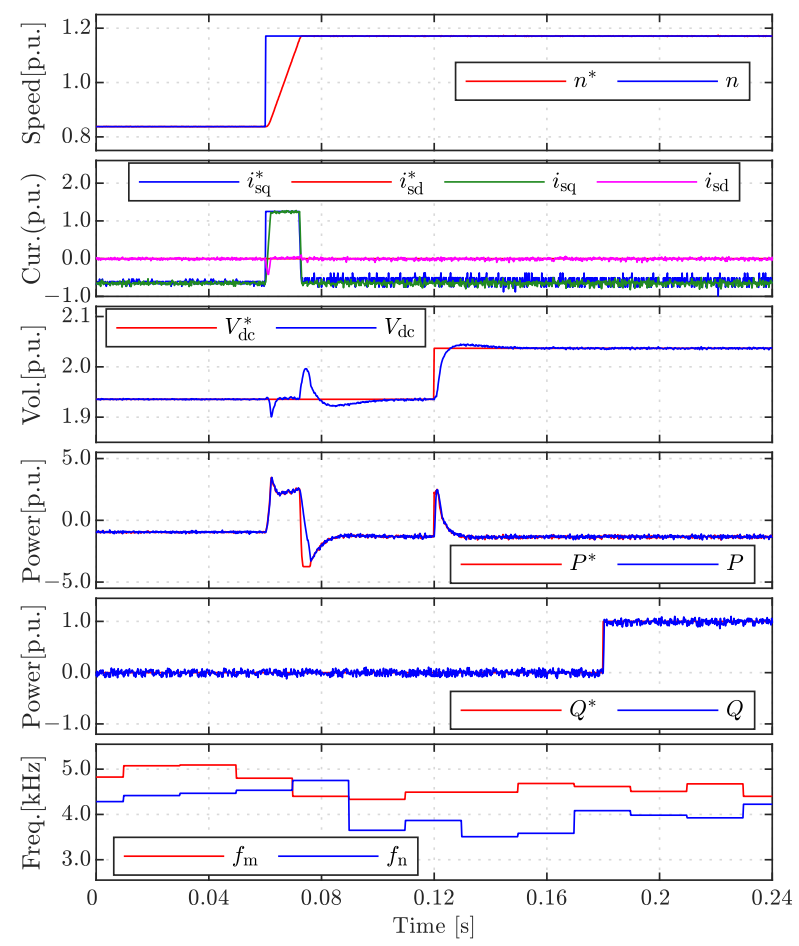

(c) Even-handed sequential MPC factor

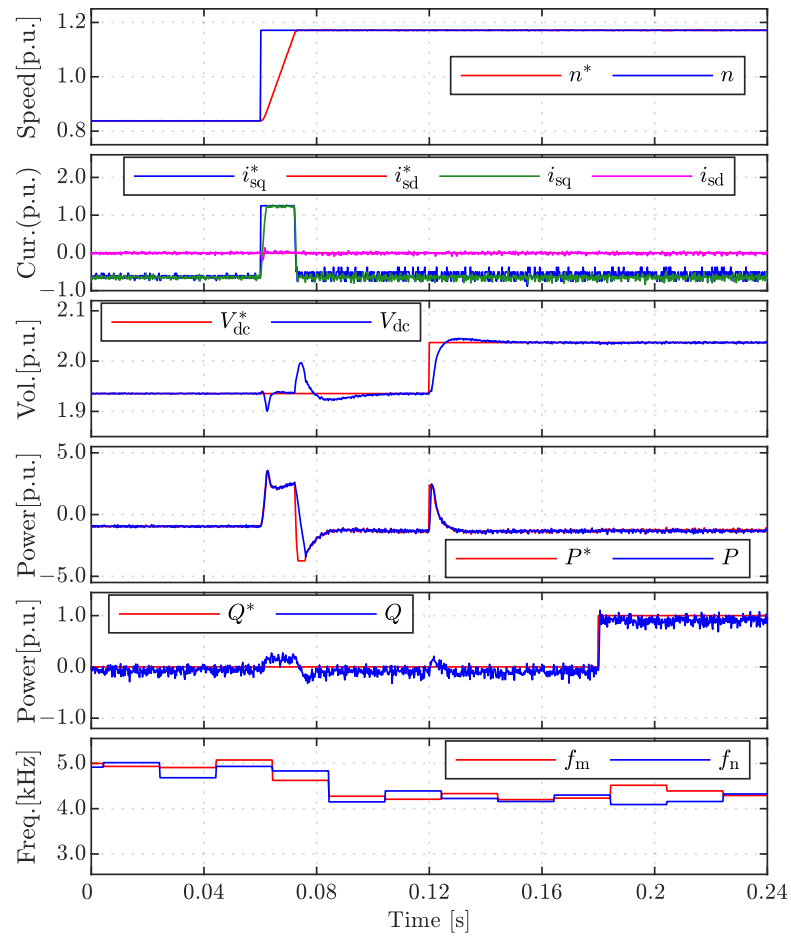

(b) Sequential MPC (SMPC)

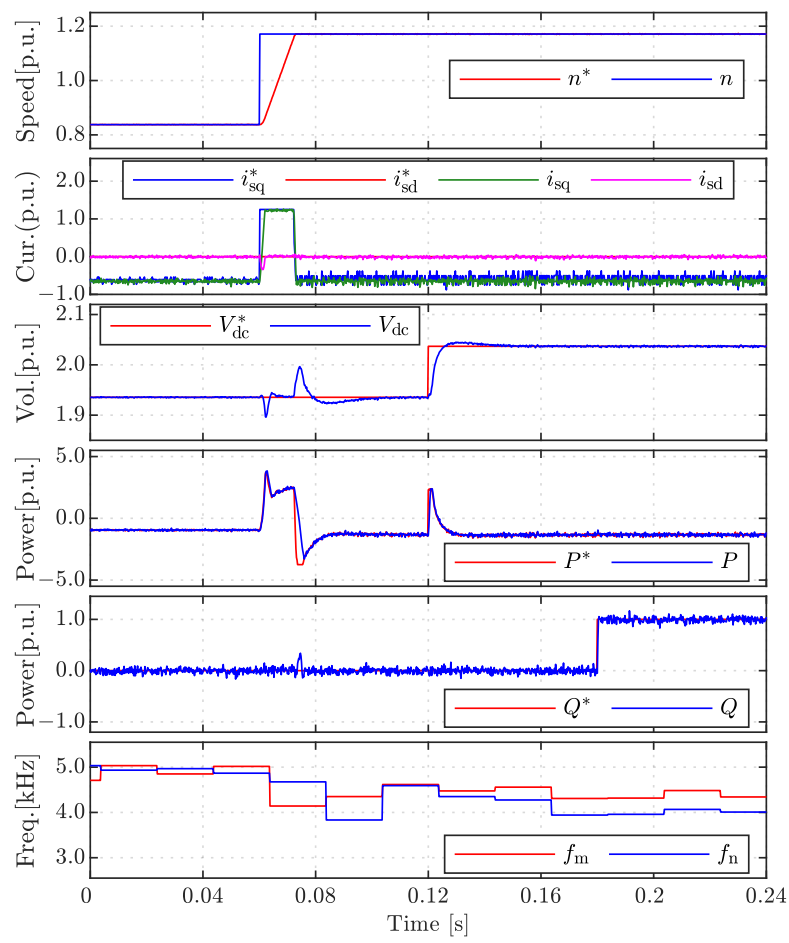

(d) MPC with online-tuned weighting factor

Fig. 10. Overall control performances for Case A (without parameter mismatch): (a) Classical model predictive control (CMPC); (b) sequential model predictive control (SMPC); (c) even-handed sequential model predictive control; (d) model predictive control with online-tuned weighting factor. Each subfigure, from the top to the bottom, respectively: speed, machine-side current, the dc-link voltage, grid-side active power, grid-side reactive power, and average switching frequency.

\section{CONCLUSION}

The weighting factor design in the predictive control of power converters for renewable energy conversion, electric drives and smart/micro-grids has been faced with challenges. Several researchers have resorted to some design methods that reduce the powerful optimal control potentials of MPC. 


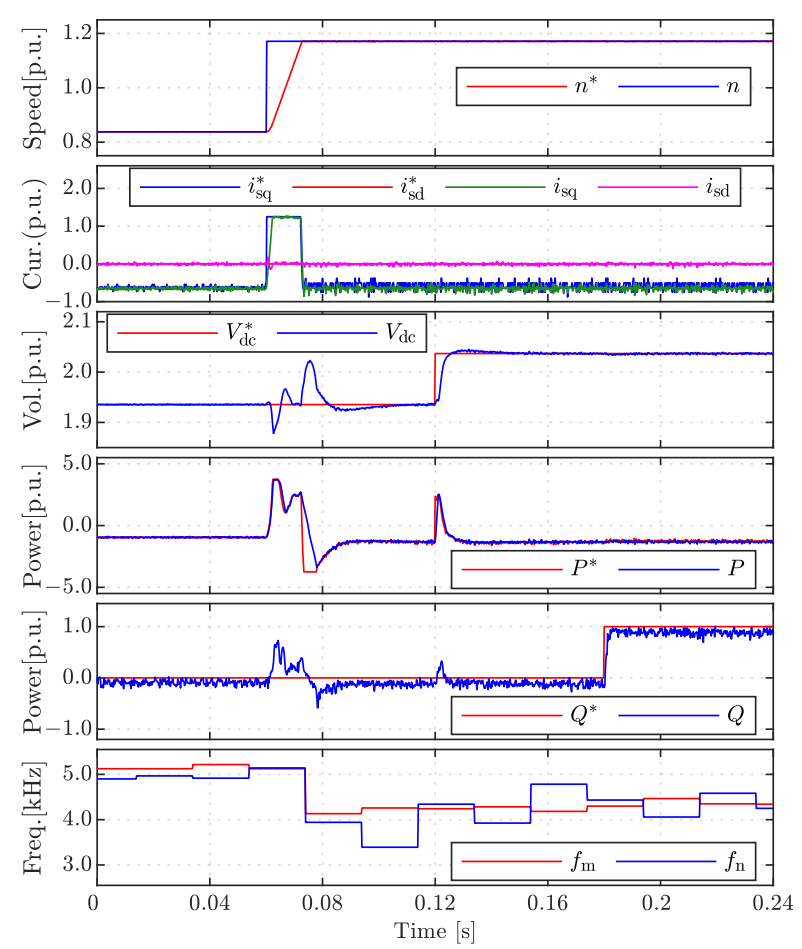

(a) Classical MPC (CMPC)

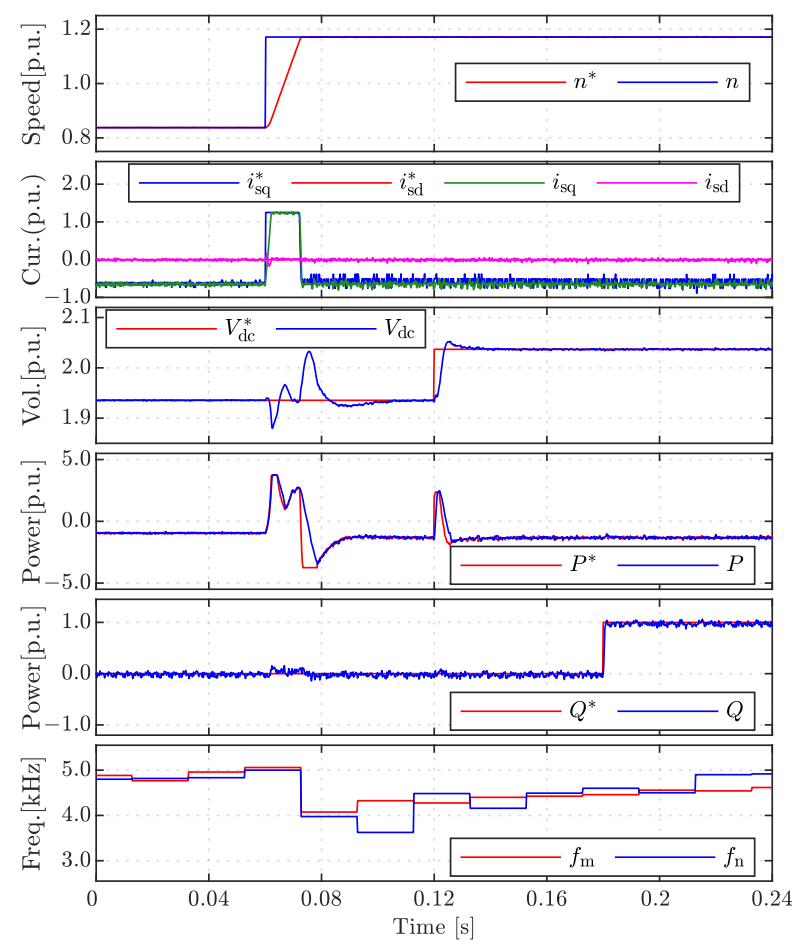

(c) Even-handed sequential MPC factor

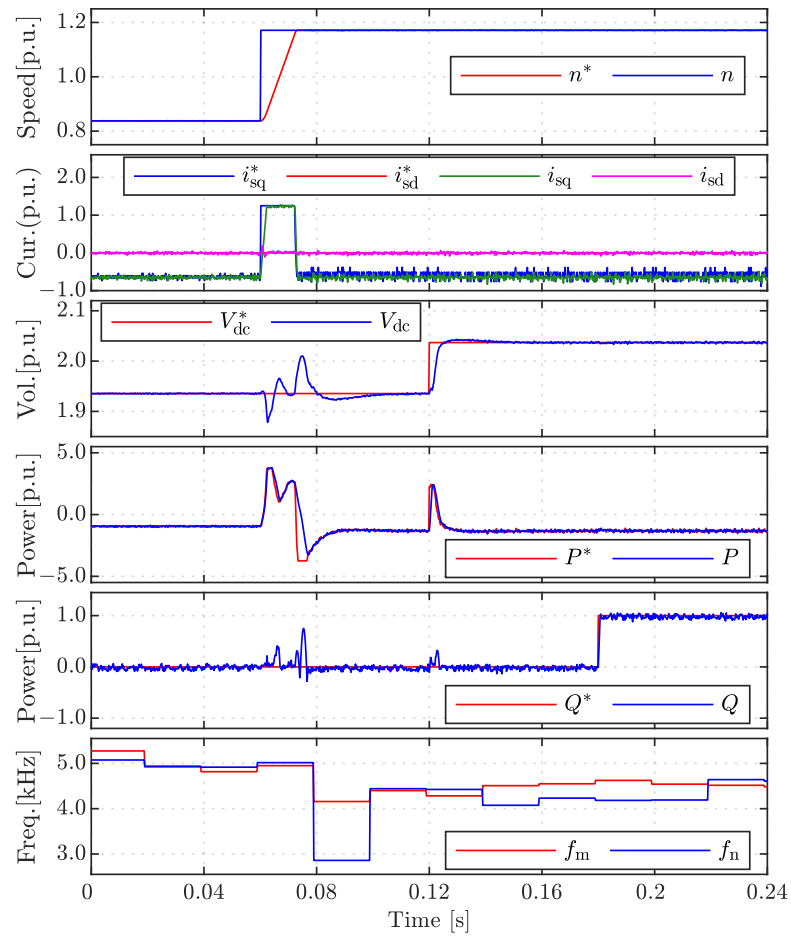

(b) Sequential MPC (SMPC)

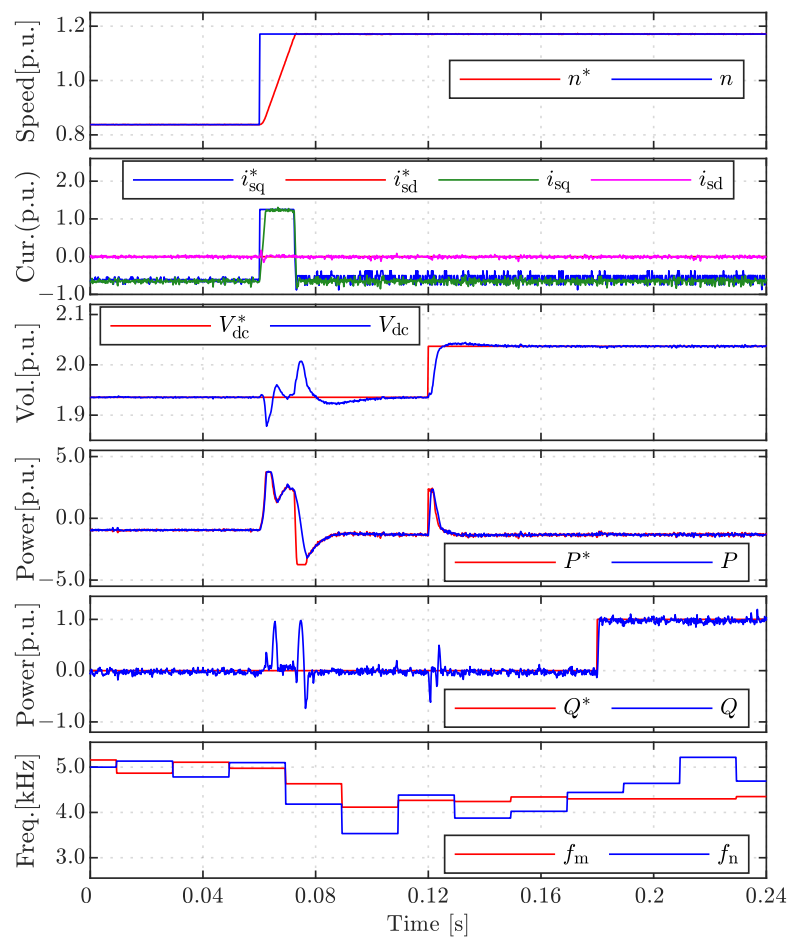

(d) MPC with online-tuned weighting factor

Fig. 11. Overall control performances for Case B (with parameter mismatch): (a) Classical model predictive control (CMPC); (b) sequential model predictive control (SMPC); (c) even-handed sequential model predictive control; (d) model predictive control with online-tuned weighting factor. Each sub-figure, from the top to the bottom, respectively: speed, machine-side current, the dc-link voltage, grid-side active power, grid-side reactive power, and average switching frequency.

This paper has reported a comparison of the state-of-the-art methods of weighting factor design. First, the review reveals that: 1) the heuristic tuning of weighting factors does not give the most optimal control performance, 2) online optimization sustains the distinctive optimal control properties of MPC, 3) simplified-model-based MPC can reduce the computation 
time of complex systems, 4) sequential MPC could reduce the optimal control power of MPC. Second, the capabilities of four methods were assessed through real-time HiL tests on a two-level back-to-back power converter-based permanent magnet synchronous generator wind turbine system. The Hil results show that even-handed sequential MPC had the overall best reactive power tracking performance during transients, and also under model parameter uncertainties; it also produced the least ripples. Sequential MPC and online-tuned weighting factor methods provided a little better robustness to parameter mismatch than classical MPC with heuristically-tuned weighting factors.

\section{REFERENCES}

[1] P. Karamanakos and T. Geyer, "Guidelines for the Design of Finite Control Set Model Predictive Controllers," IEEE Transactions on Power Electronics, vol. 35, no. 7, pp. 7434-7450.

[2] S. Vazquez, J. Rodriguez, M. Rivera, L. G. Franquelo, and M. Norambuena, "Model predictive control for power converters and drives: Advances and trends," IEEE Transactions on Industrial Electronics, vol. 64, no. 2, pp. 935-947, feb 2016.

[3] M. Norambuena, J. Rodriguez, Z. Zhang, F. Wang, C. Garcia, and R. Kennel, "A Very Simple Strategy for High-Quality Performance of AC Machines Using Model Predictive Control," IEEE Transactions on Power Electronics, vol. 34, no. 1, pp. 794-800.

[4] Z. Zhang, Z. Li, M. P. Kazmierkowski, J. Rodriguez, and R. Kennel, "Robust Predictive Control of Three-Level NPC Back-to-Back Power Converter PMSG Wind Turbine Systems with Revised Predictions," IEEE Transactions on Power Electronics, vol. 33, no. 11, pp. 95889598, nov 2018

[5] J. Zhang, L. Li, D. G. Dorrell, M. Norambuena, and J. Rodriguez, "Predictive Voltage Control of Direct Matrix Converters with Improved Output Voltage for Renewable Distributed Generation," IEEE Journal of Emerging and Selected Topics in Power Electronics, vol. 7, no. 1, pp. 296-308, 2019.

[6] M. F. Elmorshedy, W. Xu, S. M. Allam, J. Rodriguez, and C. Garcia, "MTPA-Based Finite-Set Model Predictive Control Without Weighting Factors for Linear Induction Machine," IEEE Transactions on Industrial Electronics, vol. 68, no. 3, pp. 2034-2047.

[7] X. Li, H. Zhang, M. B. Shadmand, and R. S. Balog, "Model Predictive Control of a Voltage-Source Inverter with Seamless Transition between Islanded and Grid-Connected Operations," IEEE Transactions on Industrial Electronics, vol. 64, no. 10, pp. 7906-7918, oct 2017.

[8] P. R. U. Guazzelli, W. C. d. A. Pereira, C. M. R. d. Oliveira, A. G. d Castro, and M. L. d. Aguiar, "Weighting Factors Optimization of Predictive Torque Control of Induction Motor by Multiobjective Genetic Algorithm," IEEE Transactions on Power Electronics, vol. 34, no. 7, pp. $6628-6638$

[9] M. Novak, H. Xie, T. Dragicevic, F. Wang, J. Rodriguez, and F. Blaabjerg, "Optimal Cost Function Parameter Design in Predictive Torque Control (PTC) Using Artificial Neural Networks (ANN)," IEEE Transactions on Industrial Electronics, pp. 1-1.

[10] S. Vazquez, J. I. Leon, L. G. Franquelo, J. Rodriguez, H. A. Young, A. Marquez, and P. Zanchetta, "Model predictive control: A review of its applications in power electronics," IEEE industrial electronics magazine, vol. 8, no. 1, pp. 16-31, 2014.

[11] P. Karamanakos, E. Liegmann, T. Geyer, and R. Kennel, "Model Predictive Control of Power Electronic Systems: Methods, Results, and Challenges," IEEE Open Journal of Industry Applications, vol. 1, pp. 95-114.

[12] D. F. Valencia, R. Tarvirdilu-Asl, C. Garcia, J. Rodriguez, and A. Emadi, "A review of predictive control techniques for switched reluctance machine drives. part i: Fundamentals and current control," IEEE Transactions on Energy Conversion, vol. 36, pp. 1313-1322, 2021.

[13] _ "A review of predictive control techniques for switched reluctance machine drives. part ii: Torque control, assessment and challenges," IEEE Transactions on Energy Conversion, vol. 36, pp. 1323-1335, 2021.

[14] P. Karamanakos, T. Geyer, and R. Kennel, "Reformulation of the long-horizon direct model predictive control problem to reduce the computational effort," in 2014 IEEE Energy Conversion Congress and Exposition (ECCE). IEEE, 2014, pp. 3512-3519.
[15] O. Babayomi, Z. Li, Z. Zhang, Y. Sun, T. Dragicevic, and J. Rodriguez, "The role of model predictive control in microgrid power quality - a survey." Dubrovnik, Croatia: IEEE, 2020, pp. 340-345.

[16] O. Babayomi, Y. Li, Z. Zhang, R. Kennel, and J. Kang, "Overview of model predictive control of converters for islanded ac microgrids." Nanjing, China: IEEE, 2020, pp. 1023-1028.

[17] T. Geyer, Model predictive control of high power converters and industrial drives. John Wiley \& Sons, 2016.

[18] D.-K. Choi and K.-B. Lee, "Dynamic performance improvement of ac/dc converter using model predictive direct power control with finite control set," IEEE Transactions on Industrial Electronics, vol. 62, pp. 757-767, 2015.

[19] Y. Zhang, W. Xie, Z. Li, and Y. Zhang, "Model predictive direct power control of a pwm rectifier with duty cycle optimization," IEEE Transactions on Power Electronics, vol. 28, pp. 5343-5351, 2013.

[20] Z. Zhang, H. Fang, F. Gao, J. Rodríguez, and R. Kennel, "MultipleVector Model Predictive Power Control for Grid-Tied Wind Turbine System With Enhanced Steady-State Control Performance," IEEE Transactions on Industrial Electronics, vol. 64, no. 8, pp. 6287-6298.

[21] P. Cortes, S. Kouro, B. La Rocca, R. Vargas, J. Rodriguez, J. I. Leon, S. Vazquez, and L. G. Franquelo, "Guidelines for weighting factors design in Model Predictive Control of power converters and drives," in 2009 IEEE International Conference on Industrial Technology, pp. $1-7$

[22] Z. Cui, Z. Zhang, T. Dragicevi?, and J. Rodríguez, "Dynamic Sequential Model Predictive Control of Three-Level NPC Back-to-Back Power Converter PMSG Wind Turbine Systems," in IECON 2020 The 46th Annual Conference of the IEEE Industrial Electronics Society, pp. 32063211, iSSN: 2577-1647.

[23] S. A. Davari, M. Norambuena, V. Nekoukar, C. Garcia, and J. Rodriguez, "Even-Handed Sequential Predictive Torque and Flux Control," IEEE Transactions on Industrial Electronics, vol. 67, no. 9, pp. 7334-7342.

[24] Y. Zhang, R. Wang, T. Zhang, Y. Liu, and B. Guo, "Model predictive control-based operation management for a residential microgrid with considering forecast uncertainties and demand response strategies," IET Generation, Transmission and Distribution, vol. 10, no. 10, pp. 23672378, 2016.

[25] C. A. Rojas, J. Rodriguez, F. Villarroel, J. R. Espinoza, C. A. Silva, and M. Trincado, "Predictive Torque and Flux Control Without Weighting Factors," IEEE Transactions on Industrial Electronics, vol. 60, no. 2, pp. 681-690.

[26] Y. Zhang, B. Zhang, H. Yang, M. Norambuena, and J. Rodriguez, "Generalized Sequential Model Predictive Control of IM Drives With Field-Weakening Ability," IEEE Transactions on Power Electronics, vol. 34 , no. 9 , pp. 8944-8955.

[27] J.-W. Moon, J.-S. Gwon, J.-W. Park, D.-W. Kang, and J.-M. Kim, "Model predictive control with a reduced number of considered states in a modular multilevel converter for hvdc system," IEEE Transactions on Power Delivery, vol. 30, pp. 608-617, 2015.

[28] M. B. Shadmand, S. Jain, and R. S. Balog, "Autotuning technique for the cost function weight factors in model predictive control for power electronic interfaces," IEEE Journal of Emerging and Selected Topics in Power Electronics, vol. 7, pp. 1408-1420, 2019.

[29] A. Kaymanesh, A. Chandra, and K. Al-Haddad, "Model Predictive Control of MPUC7-Based STATCOM Using Autotuned Weighting Factors,' IEEE Transactions on Industrial Electronics, pp. 1-1.

[30] Y. Zhang and H. Yang, "Model-Predictive Flux Control of Induction Motor Drives With Switching Instant Optimization," IEEE Transactions on Energy Conversion, vol. 30, no. 3, pp. 1113-1122.

[31] Z. Zhang, H. Fang, and R. Kennel, "Novel ripple reduced Direct Model Predictive Control of three-level NPC active front end with reduced computational effort," in Proceedings - 2015 IEEE International Symposium on Predictive Control of Electrical Drives and Power Electronics, PRECEDE 2015. Institute of Electrical and Electronics Engineers Inc., jan 2016, pp. 32-37.

[32] R. E. K. Meesala, V. P. K. Kunisetti, and V. K. Thippiripati, "Enhanced Predictive Torque Control for Open End Winding Induction Motor Drive Without Weighting Factor Assignment," IEEE Transactions on Power Electronics, vol. 34, no. 1, pp. 503-513.

[33] I. Jlassi and A. J. M. Cardoso, "Enhanced and Computationally Efficient Model Predictive Flux and Power Control of PMSG Drives for Wind Turbine Applications," IEEE Transactions on Industrial Electronics, pp. $1-1$.

[34] X. Lin, W. Huang, W. Jiang, Y. Zhao, and S. Zhu, "Predictive Torque Control for PMSM Based on Weighting Factor Elimination and Fast Voltage Vector Selection," IEEE Journal of Emerging and Selected Topics in Power Electronics, vol. 8, no. 4, pp. 3736-3750. 
[35] Y. Luo and C. Liu, "A Flux Constrained Predictive Control for a SixPhase PMSM Motor With Lower Complexity," IEEE Transactions on Industrial Electronics, vol. 66, no. 7, pp. 5081-5093.

[36] Y. Yang, H. Wen, M. Fan, M. Xie, and R. Chen, "Fast Finite-SwitchingState Model Predictive Control Method Without Weighting Factors for T-Type Three-Level Three-Phase Inverters," IEEE Transactions on Industrial Informatics, vol. 15, no. 3, pp. 1298-1310.

[37] Y. Yang, H. Wen, M. Fan, M. Xie, R. Chen, and Y. Wang, "A Constant Switching Frequency Model Predictive Control Without Weighting Factors for T-Type Single-Phase Three-Level Inverters," IEEE Transactions on Industrial Electronics, vol. 66, no. 7, pp. 5153-5164

[38] Y. Yang, H. Wen, M. Fan, L. He, M. Xie, R. Chen, M. Norambuena, and J. Rodríguez, "Multiple-Voltage-Vector Model Predictive Control With Reduced Complexity for Multilevel Inverters," IEEE Transactions on Transportation Electrification, vol. 6, no. 1, pp. 105-117.

[39] T. Liu, A. Chen, C. Qin, J. Chen, and X. Li, "Double Vector Model Predictive Control to Reduce Common-Mode Voltage Without Weighting Factors for Three-Level Inverters," IEEE Transactions on Industrial Electronics, vol. 67, no. 10, pp. 8980-8990.

[40] P. Acua, L. Morán, M. Rivera, R. Aguilera, R. Burgos, and V. G. Agelidis, "A Single-Objective Predictive Control Method for a Multivariable Single-Phase Three-Level NPC Converter-Based Active Power Filter," IEEE Transactions on Industrial Electronics, vol. 62, no. 7, pp. 45984607.

[41] K. M. R. Eswar, K. V. P. Kumar, and T. V. Kumar, "A Simplified Predictive Torque Control Scheme for Open-End Winding Induction Motor Drive," IEEE Journal of Emerging and Selected Topics in Power Electronics, vol. 7, no. 2, pp. 1162-1172.

[42] H. Xu, C. Yu, C. Liu, Q. Wang, F. Liu, and F. Li, "An improved virtual capacitor algorithm for reactive power sharing in multi-paralleled distributed generators," IEEE Transactions on Power Electronics, vol. 34, pp. 10786-10795, 2019.

[43] E.-S. Jun, M. H. Nguyen, and S.-S. Kwak, "Model Predictive Control Method With NP Voltage Balance by Offset Voltage Injection for ThreePhase Three-Level NPC Inverter," IEEE Access, vol. 8, pp. 172 175172195.

[44] X. Liu, D. Wang, and Z. Peng, "A Computationally Efficient FCS-MPC Method Without Weighting Factors for NNPCs With Optimal Duty Cycle Control," IEEE/ASME Transactions on Mechatronics, vol. 23, no. 5, pp. 2503-2514

[45] M. Siami, D. Arab Khaburi, and J. Rodriguez, "Simplified Finite Control Set-Model Predictive Control for Matrix Converter-Fed PMSM Drives," IEEE Transactions on Power Electronics, vol. 33, no. 3, pp. 2438-2446.

[46] W. Song, Z. Deng, S. Wang, and X. Feng, "A Simple Model Predictive Power Control Strategy for Single-Phase PWM Converters With Modulation Function Optimization," IEEE Transactions on Power Electronics, vol. 31, no. 7, pp. 5279-5289.

[47] Y. Xu, Y. He, and S. Li, "Logical Operation-Based Model Predictive Control for Quasi-Z-Source Inverter Without Weighting Factor," IEEE Journal of Emerging and Selected Topics in Power Electronics, vol. 9, no. 1 , pp. 1039-1051.

[48] J. Huang, B. Yang, F. Guo, Z. Wang, X. Tong, A. Zhang, and J. Xiao, "Priority Sorting Approach for Modular Multilevel Converter Based on Simplified Model Predictive Control," IEEE Transactions on Industrial Electronics, vol. 65, no. 6, pp. 4819-4830.

[49] Y. Jin, Q. Xiao, H. Jia, Y. Mu, Y. Ji, T. Dragi?evi?, R. Teodorescu, and F. Blaabjerg, "A Novel Sliding-Discrete-Control-Set Modulated Model Predictive Control for Modular Multilevel Converter," IEEE Access, vol. 9, pp. 10316-10327.

[50] J. Wang, X. Liu, Q. Xiao, D. Zhou, H. Qiu, and Y. Tang, "Modulated Model Predictive Control for Modular Multilevel Converters With Easy Implementation and Enhanced Steady-State Performance," IEEE Transactions on Power Electronics, vol. 35, no. 9, pp. 9107-9118.

[51] H. Mahmoudi, M. Aleenejad, and R. Ahmadi, "Modulated Model Predictive Control of Modular Multilevel Converters in VSC-HVDC Systems," IEEE Transactions on Power Delivery, vol. 33, no. 5, pp. $2115-2124$.

[52] A. Dekka, B. Wu, V. Yaramasu, R. L. Fuentes, and N. R. Zargari, "Model Predictive Control of High-Power Modular Multilevel Converters-An Overview," IEEE Journal of Emerging and Selected Topics in Power Electronics, vol. 7, no. 1, pp. 168-183.

[53] S. Zhao, F. Blaabjerg, and H. Wang, "An overview of artificial intelligence applications for power electronics," IEEE Transactions on Power Electronics, vol. 36, pp. 4633-4658, 2021.

[54] F. Villarroel, J. R. Espinoza, C. A. Rojas, J. Rodriguez, M. Rivera, and D. Sbarbaro, "Multiobjective Switching State Selector for Finite-States Model Predictive Control Based on Fuzzy Decision Making in a Matrix
Converter," IEEE Transactions on Industrial Electronics, vol. 60, no. 2 , pp. 589-599.

[55] Z. Zhang, W. Tian, W. Xiong, and R. Kennel, "Predictive torque control of induction machines fed by 3L-NPC converters with online weighting factor adjustment using Fuzzy Logic," in 2017 IEEE Transportation Electrification Conference and Expo (ITEC), pp. 84-89.

[56] H. Mahmoudi, M. Aleenejad, P. Moamaei, and R. Ahmadi, "Fuzzy adjustment of weighting factor in model predictive control of permanent magnet synchronous machines using current membership functions," in 2016 IEEE Power and Energy Conference at Illinois (PECI), pp. 1-5.

[57] S. Wang, P. Dehghanian, M. Alhazmi, and M. Nazemi, "Advanced control solutions for enhanced resilience of modern power-electronicinterfaced distribution systems," Journal of Modern Power Systems and Clean Energy, vol. 7, no. 4, pp. 716-730, 2019.

[58] X. Zhou, F. Tang, P. C. Loh, X. Jin, and W. Cao, "Four-leg converters with improved common current sharing and selective voltage-quality enhancement for islanded microgrids," IEEE Transactions on Power Delivery, vol. 31, pp. 522-531, 2016.

[59] C. A. Rojas, J. R. Rodriguez, S. Kouro, and F. Villarroel, "Multiobjective Fuzzy-Decision-Making Predictive Torque Control for an Induction Motor Drive," IEEE Transactions on Power Electronics, vol. 32, no. 8 , pp. $6245-6260$.

[60] M. J. Lesani, H. Mahmoudi, M. Ebrahim, S. Varzali, and D. Arab khaburi, "Predictive torque control of induction motor based on improved fuzzy control method," in 2013 13th Iranian Conference on Fuzzy Systems (IFSC), pp. 1-5.

[61] H. Mahmoudi, M. j. Lesani, and D. Arab khabouri, "Online fuzzy tuning of weighting factor in model predictive control of PMSM," in 2013 13th Iranian Conference on Fuzzy Systems (IFSC), pp. 1-5.

[62] M. H. Arshad, M. A. Abido, A. Salem, and A. H. Elsayed, "Weighting Factors Optimization of Model Predictive Torque Control of Induction Motor Using NSGA-II With TOPSIS Decision Making," IEEE Access, vol. 7, pp. $177595-177606$.

[63] O. Machado, P. Martín, F. J. Rodríguez, and E. J. Bueno, "A Neural Network-Based Dynamic Cost Function for the Implementation of a Predictive Current Controller," IEEE Transactions on Industrial Informatics, vol. 13, no. 6, pp. 2946-2955.

[64] T. Dragicevic and M. Novak, "Weighting Factor Design in Model Predictive Control of Power Electronic Converters: An Artificial Neural Network Approach," IEEE Transactions on Industrial Electronics, vol. 66 , no. 11 , pp. $8870-8880$.

[65] M. Babaie, M. Mehrasa, M. Sharifzadeh, and K. Al-Haddad, "Floating Weighting Factors ANN-MPC Based on Lyapunov Stability for SevenLevel Modified PUC Active Rectifier," IEEE Transactions on Industrial Electronics, pp. 1-1.

[66] Y. Yang, J. Pan, H. Wen, X. Zhang, Y. Wang, and W. Perdikakis, "Model Predictive Control with Auto-tuning Weighting Factors for Singlephase Six-Level Hybrid-Clamped Converters," IEEE Transactions on Industrial Electronics, pp. 1-1.

[67] M. Easley, S. Jain, M. Shadmand, and H. Abu-Rub, "Autonomous Model Predictive Controlled Smart Inverter With Proactive Grid Fault RideThrough Capability," IEEE Transactions on Energy Conversion, vol. 35, no. 4 , pp. $1825-1836$

[68] N. Guler, S. Biricik, S. Bayhan, and H. Komurcugil, "Model Predictive Control of DC-DC SEPIC Converters with Auto-tuning Weighting Factor," IEEE Transactions on Industrial Electronics, pp. 1-1.

[69] S. A. Davari, D. A. Khaburi, and R. Kennel, "An improved fcs-mpc algorithm for an induction motor with an imposed optimized weighting factor," IEEE Transactions on Power Electronics, vol. 27, pp. 15401551, 2012.

[70] M. Uddin, S. Mekhilef, M. Rivera, and J. Rodriguez, "Predictive indirect matrix converter fed torque ripple minimization with weighting factor optimization," in 2014 International Power Electronics Conference (IPEC-Hiroshima 2014 - ECCE ASIA), pp. 3574-3581, iSSN: 21506086.

[71] A. Bhowate, M. Aware, and S. Sharma, "Predictive Torque Control With Online Weighting Factor Computation Technique to Improve Performance of Induction Motor Drive in Low Speed Region," IEEE Access, vol. 7, pp. 42309-42321.

[72] C. Gong, Y. Hu, M. Ma, J. Gao, and K. Shen, "Novel Analytical Weighting Factor Tuning Strategy Based on State Normalization and Variable Sensitivity Balance for PMSM FCS-MPTC," IEEE/ASME Transactions on Mechatronics, vol. 25, no. 3, pp. 1690-1694.

[73] V. Yaramasu, B. Wu, and J. Chen, "Model-Predictive Control of GridTied Four-Level Diode-Clamped Inverters for High-Power Wind Energy Conversion Systems," IEEE Transactions on Power Electronics, vol. 29, no. 6 , pp. 2861-2873. 
[74] S. A. Davari, D. A. Khaburi, and R. Kennel, "Using a weighting factor table for FCS-MPC of induction motors with extended prediction horizon," in IECON 2012 - 38th Annual Conference on IEEE Industrial Electronics Society, pp. 2086-2091, iSSN: 1553-572X.

[75] V. P. Muddineni, A. K. Bonala, and S. R. Sandepudi, "Grey Relational Analysis-Based Objective Function Optimization for Predictive Torque Control of Induction Machine," IEEE Transactions on Industry Applications, vol. 57, no. 1, pp. 835-844.

[76] L. M. Caseiro, A. M. Mendes, and S. M. Cruz, "Dynamically Weighted Optimal Switching Vector Model Predictive Control of Power Converters," IEEE Transactions on Industrial Electronics, vol. 66, no. 2, pp. 1235-1245, feb 2019

[77] T. Geyer, "Algebraic Tuning Guidelines for Model Predictive Torque and Flux Control," IEEE Transactions on Industry Applications, vol. 54, no. 5, pp. 4464-4475.

[78] Z. Zhang, C. M. Hackl, and R. Kennel, "Computationally efficient dmpc for three-level npc back-to-back converters in wind turbine systems with pmsg," IEEE Transactions on Power Electronics, vol. 32, pp. 80188034, 2017.
[79] Z. Cui, Z. Zhang, Q. Yang, and R. Kennel, "Cascaded Model Predictive Control of Three-Level NPC Back-to-Back Power Converter PMSG Wind Turbine Systems," in 2018 IEEE International Power Electronics and Application Conference and Exposition (PEAC), pp. 1-6.

[80] Y. Li, Z. Zhang, and M. P. Ka?mierkowski, "Cascaded Predictive Control for Three-Level NPC Power Converter Fed Induction Machine Drives Without Weighting Factors," in 2018 IEEE International Power Electronics and Application Conference and Exposition (PEAC), pp. 15 .

[81] D. Xiao, K. S. Alam, I. Osman, M. P. Akter, S. M. S. I. Shakib, and M. F. Rahman, "Low Complexity Model Predictive Flux Control for Three-Level Neutral-Point Clamped Inverter-Fed Induction Motor Drives Without Weighting Factor," IEEE Transactions on Industry Applications, vol. 56, no. 6, pp. 6496-6506.

[82] D. Xiao, M. P. Akter, K. Alam, R. Dutta, S. Mekhilef, and M. F. Rahman, "Cascaded Predictive Flux Control for a 3-L Active NPC Fed IM Drives Without Weighting Factor," IEEE Transactions on Energy Conversion, pp. 1-1. 